\title{
Evaluation of LDH Activity and Its Relationship with Fructose Levels in Seminal Plasma of Normospermic and Hsthenospermic Males
}

\author{
Mohammad Mostakhdem \\ Hashemi (MSc) \\ Biochemistry and Metabolic \\ Disorders Research Center, \\ Golestan University of Medical \\ Sciences, Gorgan, Iran
}

Afsaneh Tabandeh (MD)

Golestan University of Medical Sciences and Health Services, Gorgan, Iran

Hamidreza Tajari (MD) Golestan University of Medical Sciences and Health Services, Gorgan, Iran

Nasser Behnampour (PhD) Health Management and Social Development Research Center, Golestan University of Medical Sciences, Gorgan, Iran

Azadeh Aliarab(MSc)

Department of Biochemestry, Shshid Beheshti university of medical science, Tehran, Iran

Hamid Reza Joshaghani (PhD) Laboratory Sciences Research Center, Golestan University of Medical Sciences, Gorgan, Iran

Corresponding author: Hamid Reza Joshaghani

Email: Joshaghani@goums.ac.ir Tel: +989111779909

Address: Golestan University of Medical Sciences, Gorgan, Iran

Received : 07 Oct 2015

Revised: 09 Dec 2015

Accepted: 28 Feb 2016

\begin{abstract}
Background and Objectives: sperm motility mainly depends on aerobic glycolysis, and lactate dehydrogenase (LDH) is a key enzyme in the last step of this process. On the other hand, fructose is considered as the main energy source for sperm motility. Therefore, this study aimed to evaluate the LDH activity and fructose levels and their correlation with sperm motion parameters in normospermic and asthenozospermic males.

Methods: In this case-control study, 96 normospermic and 96 asthenozospermic males were enrolled. The semen samples were analyzed by computer assisted semen analysis to identify sperm motion parameters. Seminal plasma fructose levels were measured using Seliwanoff's test. LDH activity in the samples was evaluated using commercially available kits. The obtained data were analyzed by SPSS software (version 16).

Results: The levels of LDH activity and fructose concentration were not different between the two groups. There was no correlation found between $\mathrm{LDH}$ activity and fructose concentration or sperm motility parameters. However, LDH was significantly correlated with sperm concentration in both groups.

Conclusion: Although LDH activity and fructose levels seem to be influenced by sperm motility, other factors such as sperm concentration and total sperm count can also affect their seminal plasma levels. Thus, when the sperm concentrations are equal in study groups, the level of these factors are expected to be equal.

Keywords: Lactate Dehydrogenase, Fructose, Sperm Motility, CASA.
\end{abstract}




\section{INTRODUCTION}

In mammals, aerobic glycolysis is the primary source of ATP for sperm motility (1-3). The importance of glycolysable substrates is for the motility $(4,5)$, protein tyrosine phosphorylation and hyperactivtion that is crucial for capacitation(5-8) and fertilization(9, 10). The last step of glycolysis process, which is essential for continued production of ATP, is the conversion of pyruvate to lactate accompanied by oxidation of NADH to NAD ${ }^{+}$. This reaction is catalyzed by lactate dehydrogenase $(\mathrm{LDH})(11,12) . \mathrm{LDH}$ is a tetrameric protein that catalyzes the last step of glycolysis (13). Ldhc gene is expressed in male(12-16) and female(11) germ cells with the final functionally protein known as the $\mathrm{LDH}-\mathrm{C}_{4}$ (15). Although $\mathrm{LDH}-\mathrm{C}_{4}$ is considered to be specific for male germ cells(17), other isoenzymes of $\mathrm{LDH}$ can be found in sperm (18, 19). LDH-C $\mathrm{C}_{4}$ constitutes more than $80 \%$ of the total LDH activity in mature spermatozoa (20). In contrast to spermatogenic cells(15), spermatids and spermatozoa exhibit high levels of glycolysis and contain high levels of LDH$\mathrm{C}_{4}$ (also known as LDH-C) (21). LDH-C is enzymes can be determined in seminal plasma and spermatozoa due to the outward diffusion or leakage of the enzyme from sperm cell and spontaneous destruction of sperm cells (22).

On the other hand, sperm motility depends on the amount of energy produced via anaerobic glycolysis, aerobic glycolysis, and betaoxidation of endogenous substrates $(23,24)$. Fructose is a hexone secreted from seminal vesicles(25) that can be used as an energy substrate for spermatozoa in anaerobic glycolysis to release lactic acid by the LDH activity $(23,24)$. This study aimed to assess the level of LDH activity in seminal plasma of asthenospermic patients (as case group) and normospermic males (as control group), and determine its effect on sperm motion parameters. In addition, fructose levels were evaluated to investigate its correlation with LDH activity in energy metabolism required for sperm motility.

\section{MATERIAL AND METHODS Study population}

Subjects of the study included 192 males referred to a clinical laboratory for semen analysis. The subjects were equally divided into two groups based on the results of their spermiogram. The subjects were matched in terms of age to prevent the confounding role of age in interpretation of results.

The inclusion criteria consisted of the following: Total volume $>2 \mathrm{ml}$, sperm concentration $>20 \times 10^{6} \mathrm{sperm} / \mathrm{ml}$, and total sperm count $>40 \times 10^{6}$. The exclusion criteria consisted of the following: Leukocytospermia (more than $1 \times 10^{6}$ leukocytes $/ \mathrm{ml}$ of ejaculation), the presence of blood, mucosa, and pus in samples, and the period of more than 2 hours from sampling until analysis.

\section{Sample selection}

The samples with normal morphology (more than $30 \%$ of whole sperms) and normal concentration (more than $20 \times 10^{6}$ sperm $/ \mathrm{ml}$ ) with motility rate problems (total motility < $50 \%$ ) were considered as the case group, while the samples with normal morphology, normal concentration, and normal motility rate (total motility $>50 \%$ ) were considered as the control group.

\section{Semen analysis}

The semen samples were collected in sterile containers by masturbation after a sexual abstinence period of 3-7 days. Volume of the ejaculates was measured immediately and the samples were incubated at $37^{\circ} \mathrm{C}$ for $15-60$ minutes (liquefaction process). The unliquefied samples were excluded from the study. Manual semen analysis and computer aided/assisted semen analysis (CASA) were performed on the samples according to "WHO laboratory manual for the examination and processing of human semen". For each CASA, $10 \mu \mathrm{l}$ of liquefied sample were loaded on the special sperm meter chamber. The parameters reported by CASA included the following: Percentage of sperm motility subtypes (motility type a, b, c and d), sperm concentration $\left(\times 10^{6}\right.$ sperm $\left./ \mathrm{ml}\right)$, percentage of sperm motility, curvilinear velocity (VCL, $\mu \mathrm{m} / \mathrm{s}$ ), straight line velocity (VSL, $\mu \mathrm{m} / \mathrm{s}$ ), average path velocity (VAP, $\mu \mathrm{m} / \mathrm{s})$, amplitude of lateral head displacement $(\mathrm{ALH}, \mu \mathrm{m})$, linearity (LIN, \%), wobble (WOB, $\%$ ), straightness (STR, \%), beat cross frequency $(\mathrm{BCF}, \mathrm{Hz})$, and mean angular displacement (MAD, degree).

After semen analysis, the samples were centrifuged at $2500 \mathrm{rpm}$ for 10 minutes and kept at $-70{ }^{\circ} \mathrm{C}$ for further biochemical testing. 


\section{Biochemical assays}

The levels of LDH activity were assayed by a kinetic method using commercially available kits (Pars Azmoon, lot number: 93003, IR Iran). In this kinetic, lactate is converted to pyruvate (and vice versa) in synchronous with the conversion of NADH to $\mathrm{NAD}^{+}$that causes an alteration in optical density (OD). Finally, these changes are detected as concentrations by the spectrophotometer instrument. The limit of detection (LOD) for this kit was 5U/L with linearity up to $3000 \mathrm{U} / \mathrm{L}$. The samples with LDH activity higher than $3000 \mathrm{U} / \mathrm{L}$ were diluted with normal saline and the results were multiplied by dilution coefficient. Concentration of fructose was measured using "quantitative resorcinol method for measurement of fructose in seminal fluid" described by Nascimento et al. The process of analyze is briefly explained below: First, 0.5 $\mathrm{mL}$ of Seliwanoff's reagent ( 0.1 gram resorcinol and 0.1 gram urea dissolved in $100 \mathrm{~mL}$ ethanol), $25 \mu \mathrm{L}$ of fructose standard solutions $(45,60,90,150,270,300,450,600 \mathrm{mg} / \mathrm{dl})$ or sample, and $2 \mathrm{~mL}$ HCL $37 \%$ were mixed in glass tubes and placed in water bath $\left(100^{\circ} \mathrm{C}\right)$ for 5 minutes. Then, the tubes were removed and cooled, and absorbance of the standards or samples was read against reagent blank at wavelength of $546 \mathrm{~nm}$.

\section{Statistical analysis}

Statistical analysis was performed using SPSS software (version 16). After data entry, basic descriptive statistics including mean \pm standard deviation (SD) were calculated for the variables. Kolmogorov-Smirnov and ShapiroWilk tests were used to assess the normality of data distribution. Independent samples $t$-test was done to analyze the relationship between LDH activity levels and fructose concentration in the two groups. Bivariate correlation test was performed to explore the correlation of $\mathrm{LDH}$ activity levels or fructose concentrations with each other and sperm motion parameters. Pvalues $<0.05$ were considered as statistically significant. This study was approved by the local ethics committee of Golestan University of Medical Sciences (approval code: 25181693102147). Informed consent was obtained from all patients prior to beginning study procedures.

\section{RESULTS}

The mean \pm SD age of participants was $31.2 \pm 5.9$ and $30.2 \pm 5.3$ years (range: $20-45$ ) in the case and control group, respectively. The LDH activity in normospermic males was slightly higher compared to asthenospermic patients. The Pearson correlation coefficient showed no correlation between LDH activity and fructose concentration in the study groups. In addition, there was no correlation between the LDH activity levels and true corrected fructose (log sperm concentration multiplied by seminal fructose concentration). However, LDH activity had significant positive correlation with sperm concentration in the asthenospermic group $(\mathrm{P}$-value $=0.001)$ and the normospermic group (P-value $=0.0001)$. Moreover, total sperm count had a significant positive correlation with LDH activity in both groups $(\mathrm{P}$-value $=0.012)$. In the present study, LDH-C4/100 million spermatozoa ratio had a significant negative correlation with fructose concentration $(\mathrm{P}$-value $=0.033, \mathrm{r}=-0.218)$ and true corrected fructose (P-value $=0.001, r=$ $0.320)$ in the asthenospermic group. However, these correlations were not observed in the normospermic group. LDH showed no correlation with other sperm parameters such as morphology and motility parameters in the study groups.

Table 1- Mean \pm SD of total LDH activity and fructose concentration in the two groups

\begin{tabular}{cccc}
\hline & $\begin{array}{c}\text { Normospermic males } \\
\text { mean } \pm \text { SD }\end{array}$ & $\begin{array}{c}\text { Asthenozospermic males } \\
\text { mean } \pm \text { SD }\end{array}$ & P-value \\
\hline $\begin{array}{c}\text { Total LDH activity } \\
(\text { U/L) }\end{array}$ & $4849.47 \pm 2298.17$ & $4316.15 \pm 2090.11$ & 0.095 \\
$\begin{array}{c}\text { Fructose concentration } \\
(\mathrm{mg} / \mathrm{dl})\end{array}$ & $269.62 \pm 169$ & $\mathbf{2 6 2 . 0 4} \pm 154.02$ & $\mathbf{0 . 7 4 5}$ \\
\hline
\end{tabular}




\section{DISCUSSION}

LDH is one of the most essential enzymes for energy metabolism in spermatozoa. The results of our study showed no difference in total LDH activity between normospermic males and asthenospermic males with impaired sperm motility. However, there was a strong correlation between LDH activity and sperm concentration and total sperm count in intragroup analysis. According to Eliasson et al., measuring LDH-C4/100 million spermatozoa ratio is an appropriate way to assess LDH-C4 activity in seminal plasma. This ratio does not reflect leakage of the LDH-C4 from these cells, but is related to the functional integrity of the seminiferous epithelium (25). The essential role of spermatogenic cellspecific glycolytic enzymes is suggested because of their abundance in the sperm tail. Thus, spermatozoa depend on extracellular glucose, fructose, and exogenous pyruvate and lactate (26). Although, there seems to be a direct correlation between LDH activity levels and fructose concentration, our study demonstrated otherwise. RNA and protein synthesis in addition to oxygen consumption in isolated spermatocytes are stimulated by exogenous lactate but not by glucose. This is another importance of lactate for germ cells (26). Grootegoed et al. showed the conversion of glucose to lactate by Sertoli cells (27). This locally produced lactate is augmented by paracrine/autocrine factors such as transforming growth factor $\beta$, epidermal growth factor, basic fibroblast growth factor, tumor necrosis factor $\alpha$ and interleukin $1 \alpha$ (28-32), which are involved in cell-cell communications in the testis (33). These factors target glucose uptake and total LDH activity for stimulating lactate production. Eliason et al. conducted a study on five groups with different fertility potencies (25) and found no relationship between $\mathrm{LDH} / 100$ million spermatozoa ratio and percentages of motile sperms, and live spermatozoa with normal relationship between LDH and sperm count (only in fertile group), which is inconsistent with the findings of our study. The mentioned study claimed that the lower amounts of $\mathrm{LDH} / \mathrm{sperm}$ ratio leads to improvement of testicular status in males over a certain timeperiod. Since the proven infertile men were not included in the criteria of case group, it is expectable that some fertile males exist in this group. On the other hand, the significance of mentioned correlations can confirm the leakage of this enzyme from spermatozoa. In the study of Casano et al., LDH activity of oligospermic patients was higher than norospermic males, while it is inversely correlated with sperm concentration and percentage of motile sperms in both groups (34). In the present study, there was no correlation between the mentioned variables and LDH levels. However, the present study separated case and control subjects based on total sperm motility (subjects had normal sperm count), while the aforementioned study separated the subjects according to sperm count. Orlando et al. evaluated total LDH and LDH- $\mathrm{C}_{4}$ activity in normospermic and oligospermic males and reported that the activity of total LDH was 2.2 times higher in oligospermic males than in normospermic males. They also reported a negative correlation between LDH activity and sperm concentration (35). Noguera et al. found that $\mathrm{LDH}-\mathrm{C}_{4}$ activity level differs significantly between fertile and infertile males (36). They also reported that LDH- $\mathrm{C}_{4}$ is significantly correlated with sperm count, which is in agreement with our findings. The LDH/count ratio had a strong relationship with sperm viability variables. The $\mathrm{LDH}-\mathrm{C}_{4}$ activity levels between two groups in some studies are opposit of our results, however, we assessed total LDH activity levels instead of $\mathrm{LDH}-\mathrm{C}_{4}$ isoenzyme, and the two studies categorized their subjects differently. Sawane et al. measured LDH activity levels in normospermic, oligospermic, and azoospermic individuals and found no statistical difference between the groups, while $\mathrm{LDH}-\mathrm{C}_{4}$ activity had a strong linear correlation with sperm concentration (37). There was also a correlation between percent of motile sperms and $\mathrm{LDH}-\mathrm{C}_{4}$ activity level, but not the percent of normal morphology. In contrast, our findings showed a correlation between the percent of motile sperms and the percent of normal morphology. However, we did not find the correlation between LDH and percent of motile sperms. In the study of Tsujii et al., the mean \pm SD of total $\mathrm{LDH}$ activity was $2.487 \pm 1.384 \mathrm{IU} / \mathrm{ml}$ in sterile males, which is notably lower than the result obtained in the present study (38). Moreover, they could not detect any correlation between sperm count and total LDH activity, while these variables had the highest correlation coefficient in the present study. Orlando et al. reported a threefold decrease in the $\mathrm{LDH}-\mathrm{C}_{4}$ activity in seminal plasma of oligospermic 
patients compared to normospermic males (14). They also found a direct relationship between LDH-C $\mathrm{C}_{4}$ activity level and sperm count in both groups, while there was no correlation between $\mathrm{LDH}_{-} \mathrm{C}_{4}$ with percentage of progressive motility, sperm viability and sperm morphology. De Burgos et al. also did not observe the correlation between LDH and percent of live spermatozoa (39). In this regard, the present study did not assess percentage of live spermatozoa, and thus cannot be compared to these studies. Gavella et al. conducted a study on 1000 sterile males and found five cases with normal sperm concentration and no sperm-specific $\mathrm{LDH}_{-} \mathrm{C}_{4}$ (40). The only abnormality observed in these subjects was reduced sperm motility and absence of $\mathrm{LDH}-\mathrm{C}_{4}$ activity, which are not consistent with the present study.

Overall, we could not relate low total LDH activity to decreased rate of sperm motility, while a significant positive correlation was found for total count and sperm concentration

\section{REFERENCES}

1. Miki K. Energy metabolism and sperm function. Society of Reproduction and Fertility supplement. 2006; 65: 309-25.

2. Miki K, Qu W, Goulding EH, Willis WD, Bunch DO, Strader LF, et al. Glyceraldehyde 3-phosphate dehydrogenase-S, a sperm-specific glycolytic enzyme, is required for sperm motility and male fertility. Proceedings of the National Academy of Sciences of the United States of America. 2004; 101(47): 16501-6.

3. Odet F, Gabel SA, Williams J, London RE, Goldberg E, Eddy EM. Lactate dehydrogenase $C$ and energy metabolism in mouse sperm. Biology of reproduction. 2011; 85(3): 556-64.

4. Mukai C, Okuno M. Glycolysis plays a major role for adenosine triphosphate supplementation in mouse sperm flagellar movement. Biology of Reproduction. 2004; 71(2): 540-7.

5. Williams AC, FORD WCL. The role of glucose in supporting motility and capacitation in human spermatozoa. Journal of Andrology. 2001; 22(4): 680-95.

6. Travis AJ, Jorgez CJ, Merdiushev T, Jones BH, Dess DM, Diaz-Cueto L, et al. Functional relationships between capacitation-dependent cell signaling and compartmentalized metabolic pathways in murine spermatozoa. Journal of Biological Chemistry. 2001; 276(10): 7630-6.

7. Urner F, Leppens-Luisier G, Sakkas D. Protein tyrosine phosphorylation in sperm during gamete interaction in the mouse: the influence of glucose. Biology of reproduction. 2001; 64(5): 1350-7.

8. Urner F, Sakkas D. Protein phosphorylation in mammalian spermatozoa. Reproduction. 2003; 125(1): 17 26. with total LDH activity.

\section{CONCLUSION}

Although LDH is one of the key enzymes involved in energy metabolism pathway of spermatozoa that seems to directly affect sperm motility, our results have demonstrated otherwise. Total LDH activity level is more influenced by sperm concentration and total sperm count than sperm motility, and therefore cannot be used for assessing sperm motility status.

\section{ACKNOWLEDGEMENTS}

The authors would like to thank the Deputy of Research at Golestan University of Medical Sciences for financial support. They also kindly acknowledge all the participants who collaborated in this study.

\section{CONFLICT OF INTEREST}

The authors declare that they have no conflict of interests.

9. Bone W, Jones N, Kamp G, Yeung C, Cooper T. Effect of ornidazole on fertility of male rats: inhibition of a glycolysis-related motility pattern and zona binding required for fertilization in vitro. Journal of reproduction and fertility. 2000; 118(1): 127-35.

10. Urner F, Sakkas D. Glucose participates in spermoocyte fusion in the mouse. Biology of reproduction. 1996; 55(4): 917-22.

11. Coonrod S, Vitale A, Duan C, Bristol-Gould S, Herr J, Goldberg E. Testis-Specific Lactate Dehydrogenase (LDH-C4; Ldh3) in Murine Oocytes and Preimplantation Embryos. Journal of andrology. 2006; 27(4): 502-9.

12. Goldberg E. Reproductive implications of $\mathrm{LDH}-\mathrm{C} 4$ and other testis-specific isozymes. Experimental and clinical immunogenetics. 1984; 2(2): 120-4.

13. Gupta G, Syal N. Immune Responses of Chemically Modified Homologous LDH-C4 and Their Effect on Fertility Regulation in Mice. American Journal of Reproductive Immunology. 1997; 37(2): 206-11.

14. Orlando C, Casano R, Caldini AL, Forti G, Barni T, Bonfanti L, et al. Measurement of Seminal LDH-X and Transferrin in Normal and Infertile Men. Journal of andrology. 1988; 9(3): 220-3.

15. Odet F, Duan C, Willis WD, Goulding EH, Kung A, Eddy EM, et al. Expression of the gene for mouse lactate dehydrogenase $C($ Ldhc) is required for male fertility. Biology of reproduction. 2008; 79(1): 26-34.

16. Wheat TE, Goldberg E. An allelic variant of the sperm-specific lactate dehydrogenase $\mathrm{C4} \quad(\mathrm{LDH}-\mathrm{X})$ isozyme in humans. Journal of Experimental Zoology. 1977; 202(3): 425-30. 
17. Goldberg E. Lactate dehydrogenase-X from mouse testes and spermatozoa. Methods in enzymology. 1975; 41: 318. doi:10.1016/S0076-6879(75)41072-2.

18. Krisfalusi M, Miki K, Magyar PL, O'Brien DA. Multiple glycolytic enzymes are tightly bound to the fibrous sheath of mouse spermatozoa. Biology of reproduction. 2006; 75(2): 270-8.

19. Sleight SB, Miranda PV, Plaskett N-W, Maier B, Lysiak $\mathrm{J}$, Scrable $\mathrm{H}$, et al. Isolation and proteomic analysis of mouse sperm detergent-resistant membrane fractions: evidence for dissociation of lipid rafts during capacitation. Biology of reproduction. 2005; 73(4): 721-9.

20. Zinkham WH, Blanco A, Clowry LJ. An Unusual Isozyme of Lactate Dehydrogenase in Mature Testes: Localization, Ontogeny, and Kinetic Properties. Annals of the New York Academy of Sciences. 1964; 121(2): 571 88. DOI: 10.1111/j.1749-6632.1964.tb14227.x.

21. Li S, O'Brien DA, Hou E, Versola J, Rockett D, Eddy E. Differential activity and synthesis of lactate dehydrogenase isozymes $A$ (muscle), $B$ (heart), and $C$ (testis) in mouse spermatogenic cells. Biology of reproduction. 1989; 40(1): 173-80.

22. Clausen J, Ovlisen B. Lactate dehydrogenase isoenzymes of human semen. Biochemical Journal. 1965; 97(2): 513-7.

23. Mann T, Lutwak-Mann C. Studies on the metabolism of semen. 4. Aerobic and anaerobic utilization of fructose by spermatozoa and seminal vesicles. Biochemical Journal. 1948; 43(2): 266-270.

24. Storey BT. Mammalian sperm metabolism: oxygen and sugar, friend and foe. International Journal of Developmental Biology. 2008; 52(5): 427-37. doi: 10.1387/ijdb.072522bs.

25. Eliasson R, Virji N. LDH-C4 in human seminal plasma and its relationship to testicular function. International journal of andrology. 1985; 8(3): 201-14.

26. Boussouar F, Benahmed M. Lactate and energy metabolism in male germ cells. Trends in Endocrinology \& Metabolism. 2004; 15(7): 345-50.

27. Grootegoed J, Den Boer P. Energy metabolism of spermatids: a review. Scientific basis for fertility regulation Cellular and molecular events in spermiogenesis Cambridge. 1990.

28. Riera M, Meroni S, Schteingart H, Pellizzari E, Cigorraga S. Regulation of lactate production and glucose transport as well as of glucose transporter 1 and lactate dehydrogenase A mRNA levels by basic fibroblast growth factor in rat Sertoli cells. Journal of Endocrinology. 2002; 173(2): 335-43.

29. Nehar D, Mauduit C, Boussouar F, Benahmed M. Interleukin $1 \alpha$ stimulates lactate dehydrogenase A expression and lactate production in cultured porcine Sertoli cells. Biology of reproduction. 1998; 59(6): 142532.

30. Nehar D, Mauduit C, Boussouar F, Benahmed M. Tumor Necrosis Factor- $\alpha$-Stimulated Lactate Production Is Linked to Lactate Dehydrogenase A Expression and Activity Increase in Porcine Cultured Sertoli Cells 1. Endocrinology. 1997; 138(5): 1964-71.

31. Boussouar F, Grataroli R, Ji J, Benahmed M. Tumor necrosis factor- $\alpha$ stimulates lactate dehydrogenase $A$ expression in porcine cultured Sertoli cells: mechanisms of action. Endocrinology. 1999; 140(7): 3054-62.

32. Boussouar F, Benahmed M. Epidermal growth factor regulates glucose metabolism through lactate

dehydrogenase A messenger ribonucleic acid expression in cultured porcine Sertoli cells. Biology of reproduction. 1999; 61(4): 1139-45.

33. Gnessi L, Fabbri A, Spera G. Gonadal Peptides as Mediators of Development and Functional Control of the Testis: An Integrated System with Hormones and Local Environment 1. Endocrine Reviews. 1997; 18(4): 541-609.

34. Casano R, Orlando C, Serio M, Forti G. $L D H$ and $L D H-X$ activity in sperm from normospermic and oligozoospermic men. International journal of andrology. 1991; 14(4): 257-63.

35. Orlando C, Krausz C, FORT G, Casano R Simultaneous measurement of sperm $L D H, L D H-X, C P K$ activities and ATP content in normospermic and oligozoospermic men. International journal of andrology. 1994; 17(1): 13-8.

36. Noguera VJ, Tovar ZI, Martinez HP, Perez AM, Tortosa OJ, Parrilla PJ. Lactic dehydrogenase-C4 activity in seminal plasma and male infertility. Fertility and sterility. 1993; 60(2): 331-5.

37. Sawane M, Kaore S, Gaikwad R, Patil P, Patankar S, Deshkar A. Seminal LDH-C4 isoenzyme and sperm mitochondrial activity: a study in male partners of infertile couples. Indian journal of medical sciences. 2002; 56(11): 560.

38. Tsujii T, Kamai T, Moriguchi H, Hosoya Y, Honda M, Yamanishi $\mathrm{T}$, et al. Seminal lactate dehydrogenase C4 $(\mathrm{LDH}-\mathrm{C4})$ isozyme activity in infertile men. Hinyokika kiyo Acta urologica Japonica. 2002;48(4):193-7.

39. De Burgos NG, Burgos C, Coronel C, De Camusso $\mathrm{AB}$, Pigini $\mathrm{T}$, Blanco A. Correlation of lactate dehydrogenase isoenzyme C4 activity with the count and motility of human spermatozoa. Journal of reproduction

and fertility. 1979; 55(1): 107-11.

40. Gavella M, Cvitković P. Semen LDH-X deficiency and male infertility. Archives of andrology. 1985; 15(2-3): 173-6. 